\title{
RESUlTADOS DE LA EVALUACIÓN DE SOSTENIBILIDAD DE LA ESTRUCTURA URBANA DEL ÁREA METROPOLITANA DE MENDOZA A LA LUZ DE UNA METODOLOGÍA ESPECÍFICA
}

María Emilia García Schilardi*

\section{Resumen}

Desde la década de los noventa se desarrollan fuertes procesos de urbanización a escala mundial. Son las ciudades los ámbitos en donde las personas residen y (re)producen su vida cotidiana y en donde se generan los más fuertes impactos ambientales negativos.

En este contexto, toma relevancia la consideración de características deseables de sostenibilidad urbana para la mejora de la vida cotidiana en las ciudades o sistemas urbanos del siglo Xxi. Este trabajo tiene como objetivo evaluar la sostenibilidad de la estructura urbana del área metropolitana de Mendoza a través del marco metodológico propuesto por Camagni y Pozueta. Se adopta, entonces, una metodología de análisis de información a través de indicadores expresados en tablas y cartografía. Es decir, en este artículo se presentan los resultados de aplicar una metodología y unos indicadores a la realidad cuantitativa del área metropolitana de Mendoza. Como principal resultado se detecta que el área en

* Magíster en Economía Urbana y en Ordenamiento Territorial. Candidata al Doctorado en Ordenamiento del Territorio y Desarrollo Sostenible, Universidad Nacional de Cuyo. Miembro del equipo de trabajo del Programa de Movilidad Sostenible. Instituto de Ciencias Ambientales, Universidad Nacional de Cuyo, Mendoza (Argentina). [maria-emilia-garcia@hotmail.com]

Recibido: 1 de julio 2016 / Modificado: 26 de agosto de 2016 / Aceptado: 1 de septiembre de 2016.

Para citar este artículo

García Schilardi, M. E. (2016). Resultados de la evaluación de sostenibilidad de la estructura urbana del área metropolitana de Mendoza a la luz de una metodología específica. opera, 19, pp. 83-110.

DOI: http://dx.doi.org/10.18601/16578651.n19.06 
estudio no alcanza los estándares mínimos de sostenibilidad y se proponen algunas medidas para revertir esa situación.

Palabras clave: sostenibilidad, sistema urbano, política pública, indicadores, desarrollo sostenible.

\section{RESULTS OF THE EVALUATION OF SUSTAINABILITY OF THE URBAN STRUCTURE OF THE METROPOLITAN AREA OF MENDOZA TROUGH A SPECIFIC METHODOLOGICAL FRAMEWORK}

\section{Abstract}

Since the 90's decade a strong urbanization process is developing worldwide. Cities are areas where people reside and (re) produce their daily lives and where the strongest negative environmental impacts are generated.

In this context it becomes relevant to consider the characteristics of urban sustainability to improve everyday life in cities or urban systems of the 21 st century. This work aims to evaluate the sustainability of the urban structure of the Metropolitan Area of Mendoza through the methodological framework proposed by Camagni and Pozueta. It is adopted a methodology for data analysis through indicators expressed in tables and maps. In other words, in this article they are shown the results of applying a methodology with indicators to the quantitative reality of the Metropolitan Area of Mendoza. The main result is that the study area does not meet the minimum standards of sustainability and some measures to reverse this situation are proposed.
Key words: Sustainability, urban system, public policy, indicators, sustainable development.

\section{INTRODUCCIÓN}

Las ciudades son los ámbitos en donde las personas residen y (re)producen su vida cotidiana, en donde se llevan adelante las actividades más dinámicas de la economía, y, a su vez, en donde se generan los más fuertes impactos ambientales negativos. El crecimiento explosivo, continuo y desorganizado de las ciudades tiene efectos desfavorables que afectan la calidad de vida de las personas que residen en ellas.

En este contexto, y con la finalidad de controlar y corregir los fenómenos que perjudican las condiciones de vida de las personas, surge el enfoque del desarrollo sostenible urbano. Este paradigma considera como base los mismos criterios del desarrollo sostenible solo que en un ámbito urbano: la mejora de la calidad ambiental en las ciudades, la justicia social y el crecimiento económico. Toma relevancia, entonces, la consideración de las características deseables de sostenibilidad urbana para que la política pública sea una herramienta que guíe los procesos de mejora de la vida cotidiana en las ciudades o sistemas urbanos del siglo XxI.

Este trabajo tiene como objetivo evaluar la sostenibilidad de la estructura urbana del área metropolitana de Mendoza (en adelante AMM) a través de una adaptación del marco metodológico propuesto por Camagni y Pozueta. Se adopta, entonces, una metodología 
de análisis de información a través de indicadores expresados en tablas y cartografía. Cuando resulta posible, se le asignan, a dichos indicadores, valores, y se comparan con parámetros encontrados en la literatura. Es decir, en este artículo se presentan los resultados de aplicar una metodología y unos indicadores a la realidad cuantitativa del AMM.

Como resultado general se detecta que el área bajo estudio no es un sistema urbano sustentable. No es un espacio urbano estructurado para ser sustentable. Para revertir esta situación se requiere de políticas de ordenamiento territorial y de ordenamiento de la movilidad, coordinadas entre sí.

\section{DESARROLLO SOSTENIBLE EN EL ÁMBITO URBANO}

El concepto de desarrollo sostenible se formaliza en el documento conocido como el Informe Brundtland en 1987, en donde se pone de manifiesto el vínculo entre el crecimiento económico, los recursos naturales y la sociedad. Se afirma la búsqueda del desarrollo presente sin comprometer el desarrollo de las generaciones futuras. A lo largo del tiempo, este concepto evoluciona y se detectan tres corrientes generales que representan posturas diversas. Por un lado, está la postura más laxa que propone modificar los procesos productivos para reducir los impactos negativos ambientales y sociales. Considera que la conservación es necesaria para el desarrollo económico y que para ello se debe realizar una reforma técnica de los procesos productivos (uso más eficiente de los recursos). Pone el foco en los instrumentos económicos y en la valoración económica de los recursos naturales. Por otro lado, existe una postura intermedia que afirma que no todos los recursos deben reducirse a una valoración económica, sino que la conservación es necesaria y deseable más allá de sus usos en los procesos productivos. Por último, se detecta una postura más estricta que sostiene que los recursos naturales pueden ser valorados desde muy diversos enfoques (social, cultural, ecológico, religioso, estético, etc.), siendo estos tanto o más importantes que la valoración económica. Se destaca el concepto de patrimonio natural que debe ser conservado y mantenido para el aprovechamiento y disfrute de las generaciones próximas. Esta postura rompe con la idea de crecimiento económico y pone el acento en la calidad de vida. Esta última corriente considera que una ciudad sustentable es posible si se modifica sustancialmente el paradigma de desarrollo contemporáneo.

En este marco, en la década de los noventa comienza a hablarse del desarrollo sostenible urbano a raíz de los fuertes procesos de urbanización ocurridos a escala mundial, sobre todo en países en desarrollo (Burgess, 2003). Se detecta a las ciudades como fuentes significativas de impactos ambientales negativos. Según Gudynas (2009):

La ciudad y en especial las áreas metropolitanas, fueron tradicionalmente concebidas como el extremo de "artificialización" de los ambientes naturales: por lo tanto, la ciudad pasó a ser vista como ambientalmente negativa, dependiente de la materia y energía que extrae de la naturaleza, mientras exuda hacia fuera sus desechos y efluentes (p. 13). 
Esta discusión se enmarca en un debate más amplio sobre la articulación entre ambiente y desarrollo. A fines de la década de los setenta se comienza a utilizar el concepto de "resiliencia" (la capacidad adaptativa) de las estructuras urbanas (Acselrad, 1999) que hace referencia a la apropiación de recursos naturales a una tasa que resulte, al menos, equivalente a la generación y regeneración de dichos recursos en la naturaleza. Es decir, el consumo de los recursos naturales en las ciudades no debería exceder las capacidades de los ecosistemas de reproducirlos y absorber los impactos ambientales. Esta noción de resiliencia, vinculada a la sostenibilidad, genera una gran polémica porque se contrapone al concepto de desarrollo con crecimiento constante en el tiempo propio de la economía clásica. Este enfoque es aceptado recientemente ya que es evidente que recursos como el agua y el petróleo son escasos.

El paradigma de desarrollo urbano sostenible concibe a la ciudad como un sistema compuesto por subsistemas (económico, social y físico natural) que interactúan entre sí.

Según Camagni (2005):

Podemos definir el desarrollo urbano sostenible como un proceso de integración sinérgica y de coevolución entre los grandes subsistemas que componen la ciudad (el sistema económico, el sistema social, el sistema físico - built and cultural heritage- y el sistema ambiental) que garantiza un nivel no decreciente de bienestar a la población local a largo plazo, sin comprometer las posibilidades de desarrollo de las áreas vecinas y contribuyendo a la reducción de los efectos nocivos del desarrollo sobre la biosfera (pp. 220-221).
En la consideración de la sustentabilidad urbana se detectan dos formas de crecimiento espacial de las ciudades: crecimiento vertical y crecimiento expandido en superficie incorporando al uso urbano tierras de la periferia. Según cuál de estas formas de crecimiento espacial sea dominante, y cómo se materialice en el espacio urbano, se plantea la dicotomía entre ciudades compactas y ciudades dispersas (Urriza y Garriz, 2014).

Existe vasta bibliografía (Libro Verde sobre medio ambiente urbano CEE, 1990; Agenda 21 onu, 1992; Jenks, Burton y Williams, 1996; Rueda Palenzuela, 1999; Marín Cots, 2002; sedesol México, 2009; Agencia Ecológica Urbana de Barcelona, 2010) que sostiene que la ciudad sustentable es compacta, o, en otros términos, que la ciudad compacta es la forma sustentable. La calidad de compacta representa un territorio en el cual sus elementos constituyentes se encuentran próximos entre sí, reuniendo en un espacio limitado los usos y funciones urbanos y favoreciendo los intercambios, las comunicaciones y la generación de capital social. Es decir, la compactibilidad no se refiere únicamente a los aspectos físicos o morfológicos sino también al comportamiento de la ciudad en tanto existe mezcla e interrelación de actividades, personas y bienes en un espacio delimitado. La urbanización compacta crece pero de manera racional y planificada, no desproporcionada o espontáneamente. Asimismo, según diversos autores (Moliní y Salgado, 2010 y 2012; Magrinyà y Herce, 2007; Cárdenas Ropero, 2012; Indovina, 2007; Chavoya Gama et al., 2009, citados en Urriza y Garriz, 2014) se asume a 
la ciudad con una trama urbana contigua y con densidades medias o altas.

En oposición a este concepto de ciudad compacta, y como modelo antagónico, se encuentra el de ciudad dispersa. Esta se presenta como una ciudad extensa y en expansión constante e indiscriminada, cuyos elementos o subsistemas no se encuentran próximos entre sí, invasora de territorios productivos, que utiliza los recursos naturales de manera no racional y por ello despilfarra energía; los procesos de ocupación del espacio urbano son discontinuos. En este tipo de ciudad existe una baja densidad poblacional y edilicia, que no favore el intercambio, la comunicación, la mezcla de usos, actividades, funciones y los flujos de personas y bienes. La ciudad dispersa tiende a generar áreas homogéneas y unifuncionales o monofuncionales (zonas exclusivamente residenciales, centros comerciales, zonas corporativas, parques industriales). Se observa, entonces, que las ciudades dispersas tienen costos más altos en infraestructura y servicios, en utilización de recursos naturales y en externalidades negativas, en especial contaminación ambiental. En las ciudades dispersas se genera un círculo vicioso que produce un incremento constante de estos costos. En palabras de Rueda Palenzuela (1999), si se considera al entorno como el sistema de soporte de las ciudades, se detecta que el consumo de suelo, de energía y de recursos naturales que de este se hace, como también el flujo contaminante dirigido hacia el mismo, es mayor en las ciudades dispersas que en las compactas. Se detecta que los procesos de mal aprovechamiento del suelo, la energía y los recursos naturales disponibles son causa y efecto de la inadecuada legislación sobre ocupación y tenencia del suelo y de la ausencia de un ordenamiento territorial.

Ni el modelo compacto ni el modelo disperso de ciudad se encuentran en la realidad en estado puro. La caracterización de estos modelos se justifica en tanto muestran dos polos extremos entre los cuales se situará el modelo urbano que se analice. La evaluación de la ciudad se centrará, entonces, en saber a cuál modelo se asemeja más. Es decir, mientras más cercano al modelo de ciudad compacta, más sustentable será la ciudad en estudio. En apartados siguientes se determinará una metodología específica para dicho análisis.

\section{METODOLOGÍA}

El área urbana analizada se ubica en el centro norte de la provincia de Mendoza, Argentina, y tiene una población de 990.153 habitantes. Por su extensión abarca parte del territorio de seis municipios (Capital, Godoy Cruz, Maipú, Luján de Cuyo, Guaymallén y Las Heras), y dentro del sistema de ciudades de Argentina se encuentra entre las ciudades intermedias, tanto por su población como por su funcionalidad (figura 1).

Este trabajo se basa en una adaptación del marco metodológico propuesto por Camagni (2005) y al que, con pequeñas diferencias, adhiere Pozueta (2000). El primer autor afirma que la sostenibilidad de la estructura del sistema urbano se evalúa a través de cuatro variables que dan cuenta del modo en que está constituida materialmente la ciudad: 
FIGURA 1. ÁREA METROPOLITANA DE MENDOZA
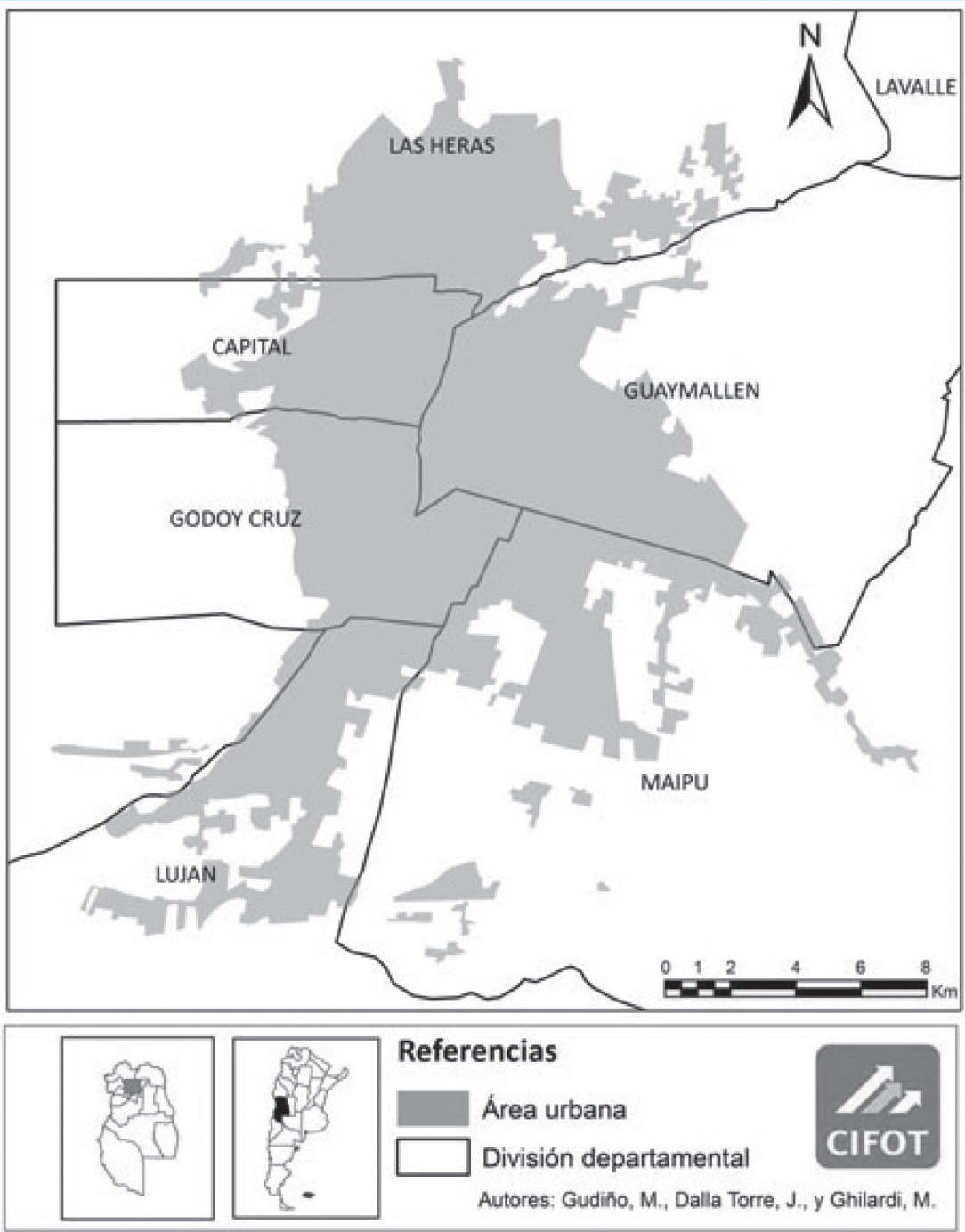

Fuente: Instituto CIFOT UNCuyo (2015).

a) Tamaño de la ciudad: se considera el tamaño absoluto y relativo de la misma. El tamaño absoluto se vincula con la cantidad de población que habita en ella, y el tamaño relativo se refiere a la posición que ocupa respecto del sistema de ciudades del que forma parte.

b) Forma urbana: como se precisó, la característica más favorable para la sostenibilidad es la ciudad compacta. Se evaluará si 
el sistema urbano tiende a ser compacto o, por el contrario, disperso. Para ello se consideran dos indicadores: área urbana por habitante y crecimiento de la mancha urbana.

c) Mezcla de usos del suelo: la integración de usos de suelo, de las funciones y actividades, y la combinación de ellos es favorable para la sostenibilidad. Para evaluar esta variable se consideran dos indicadores: proximidad a equipamientos básicos y superficie de espacios verdes por habitante.

d) Densidad de uso del suelo: hace referencia a la cantidad de usos del suelo en un espacio determinado. Una mayor densidad de uso del suelo disminuye el consumo energético, así como los costos de extensión de infraestructura para servicios de agua, gas, electricidad y alcantarillado, y aumenta el uso de medios colectivos de transporte. Esta variable se analiza a partir de dos indicadores: densidad poblacional y densidad de viviendas.

Estas variables se estudian o explican a través de los indicadores enunciados que dan cuenta de su estado en un momento en el tiempo. Se seleccionan indicadores para cada variable (tabla 1), teniendo en cuenta principalmente la relevancia para explicar la variable correspondiente y la información disponible para su cálculo. A cada variable se le asigna una ponderación del $25 \%$, es decir, todas ellas tienen la misma importancia. A su vez, los indicadores que explican a cada variable también tienen igual participación.
Finalmente, se establecen dos intervalos que determinan, en función de las variables e indicadores, si las características espaciales del sistema urbano son sostenibles o no en conjunto. Estos intervalos se establecen con un estándar alto de sostenibilidad, es decir, se deben dar en, al menos, un $75 \%$ las características deseables para que el sistema urbano sea sustentable en su dimensión espacial.

TABLA 1. CARACTERÍSTICAS ESPACIALES DEL SISTEMA URBANO

\begin{tabular}{|c|c|c|c|}
\hline Variable & Indicador & Atributo & Ponderación \\
\hline \multirow{2}{*}{$\begin{array}{l}\text { Tamaño } \\
\text { de la ciu- } \\
\text { dad }\end{array}$} & \multirow{2}{*}{$\begin{array}{l}\text { Dimensión } \\
\text { de la ciudad }\end{array}$} & Adecuada & 0,25 \\
\hline & & No adecuada & 0 \\
\hline \multirow{4}{*}{$\begin{array}{l}\text { Forma } \\
\text { urbana }\end{array}$} & \multirow{2}{*}{$\begin{array}{l}\text { Área urbana } \\
\text { por habi- } \\
\text { tante }\end{array}$} & Adecuada & 0,125 \\
\hline & & No adecuada & 0 \\
\hline & \multirow{2}{*}{$\begin{array}{l}\text { Crecimiento } \\
\text { de la man- } \\
\text { cha urbana }\end{array}$} & No acelerado & 0,125 \\
\hline & & Acelerado & 0 \\
\hline \multirow{4}{*}{$\begin{array}{l}\text { Mezcla } \\
\text { de usos }\end{array}$} & \multirow{2}{*}{$\begin{array}{l}\text { Espacios } \\
\text { verdes por } \\
\text { habitante }\end{array}$} & Suficientes & 0,125 \\
\hline & & $\begin{array}{l}\text { No suficien- } \\
\text { tes }\end{array}$ & 0 \\
\hline & \multirow{2}{*}{$\begin{array}{l}\text { Proximidad a } \\
\text { equipamien- } \\
\text { tos básicos }\end{array}$} & Suficientes & 0,125 \\
\hline & & $\begin{array}{l}\text { No suficien- } \\
\text { tes }\end{array}$ & 0 \\
\hline \multirow{6}{*}{$\begin{array}{l}\text { Densidad } \\
\text { de uso } \\
\text { del suelo }\end{array}$} & \multirow{2}{*}{$\begin{array}{l}\text { Densidad } \\
\text { poblacional }\end{array}$} & Adecuada & 0,125 \\
\hline & & No adecuada & 0 \\
\hline & \multirow{2}{*}{$\begin{array}{l}\text { Densidad de } \\
\text { viviendas }\end{array}$} & Adecuada & 0,125 \\
\hline & & No adecuada & 0 \\
\hline & \multirow{2}{*}{$\begin{array}{l}\text { Característi- } \\
\text { cas espacia- } \\
\text { les del siste- } \\
\text { ma urbano }\end{array}$} & Sustentables & 0,$75 ; 1$ \\
\hline & & $\begin{array}{l}\text { No sustenta- } \\
\text { bles }\end{array}$ & $0 ; 0,75$ \\
\hline
\end{tabular}

Fuente: elaboración propia. 


\section{ANÁLISIS DE SUSTENTABILIDAD DEL ÁREA BAJO ESTUDIO}

Siguiendo la metodología planteada, se realizará un análisis de cada una de las variables que componen la estructura territorial urbana para luego evaluar su sustentabilidad.

\section{Tamaño o dimensión de la ciudad}

El tamaño relativo de la ciudad se relaciona con la posición que ocupa cada ciudad en el sistema de ciudades y con sus características tecnológicas, sociales, políticas, ambientales y económicas. Por su parte, no existe acuerdo en la bibliografía respecto del tamaño absoluto óptimo de las ciudades.

Dentro del sistema urbano argentino se considera al AMM una ciudad intermedia por su funcionalidad. $\mathrm{Al}$ respecto, cabe decir que no existe consenso sobre los criterios que definen a la ciudad intermedia. Según Michelini y Davies (2009), existe incertidumbre en la definición cuantitativa de las ciudades intermedias, careciendo de umbrales demográficos universales por los que guiarse y caracterizando, por tanto, a las mismas según su articulación con el sistema urbano al que pertenezcan. El modo de identificar a las ciudades intermedias es a través de su consideración como "otros espacios urbanos", definiéndolas por su "negativo", no siendo estas ni pequeños pueblos ni grandes metrópolis (Bellet y Llop, 2004). Es decir, ya no se tienen solo en cuenta los criterios cuantitativos de tamaño de la población o extensión espacial, sino que se adoptan también criterios cualitativos como la función que la ciudad juega en la jerarquía de ciudades del sistema urbano, en tanto que asumen un rol de intermediarias entre los espacios rurales y las grandes ciudades. Bajo estos postulados, se considera por su funcionalidad al AMM como una ciudad intermedia, a la vez que cumple con el criterio cuantitativo de Vapñarsky (1995) que identifica a las "aglomeraciones de tamaño intermedio" (p. 228) de Argentina como aquellas mayores a 50.000 habitantes, exceptuando el Gran Buenos Aires. En este sentido, el AMM tiene una población de 990.153 habitantes.

Asimismo, el AMM cumple una función relevante de ciudad intermedia en el corredor bioceánico ya que se ubica en una posición estratégica del continente que la coloca como centro de transferencias de bienes y servicios (figura 2).

Asimismo, el AMm se presenta con un núcleo central muy fuerte, que concentra las actividades administrativas, políticas, comerciales y financieras. A la vez, existen centralidades más pequeñas, con las mismas funciones, que coinciden con las cabeceras departamentales y subcentralidades comerciales como shoppings e hipermercados. Estas subcentralidades son la primera evidencia de la tendencia hacia una forma urbana policéntrica dispersa.

Se observa que el AMM tiene una dinámica similar al resto de las ciudades latinoamericanas. Según Trivelli (2004):

El sistema de asentamientos humanos de América Latina se caracteriza por un patrón de concentración de la población en grandes ciudades, a la vez que el peso relativo de la ciudad principal es muy importante respecto al resto de los conglomerados urbanos, existiendo un gran desequilibrio territorial (p. 4). 
FIGURA 2. POSICIÓN DEL AMM EN EL CORREDOR BIOCEÁNICO

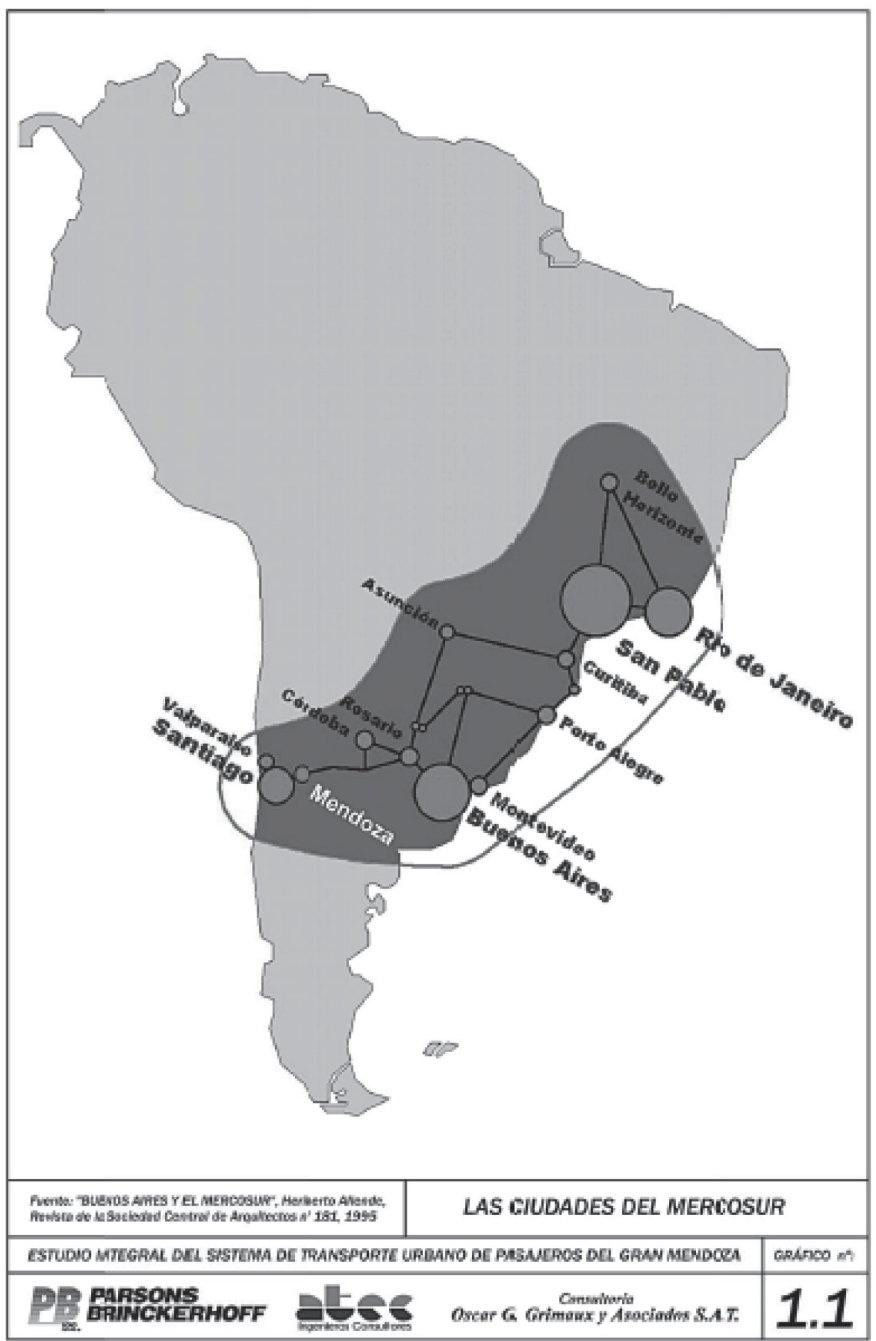

Fuente: Proyecto de Transporte Urbano en Áreas Metropolitanas de la Argentina (PTUMA) (2010).

En menor escala, en el área en estudio ocurre lo mismo. Existe un núcleo central muy fuerte y de mayor peso relativo que las subcentralidades locales (o departamentales). El área metropolitana se dispersa progresivamente desde el núcleo central, emplazándose principalmente en derredor de los principales corredores viales.

En un contexto de ausencia de organización urbana, la producción de la ciudad se realiza según indica la especulación inmobiliaria y el modelo de desarrollo de baja inter- 
vención estatal que prioriza el crecimiento económico y el libre funcionamiento del mercado, y no atiende adecuadamente, o en absoluto, las necesidades territoriales, sociales y ambientales que se generan. Es así, que en el espacio urbano se superponen, y en algunos casos contraponen, demandas del modelo de crecimiento económico y demandas de la población urbana en permanente crecimiento. Se produce, de este modo, una ciudad con expansión explosiva, discontinua, en forma de mancha de aceite ${ }^{1}$, que invade tierras antes destinadas a la actividad agrícola o que avanza sobre áreas de gran fragilidad ambiental. En términos de Razquin y Pons (1990) "la no utilización de importantes huecos urbanos incide en la consolidación urbana, tendiendo a desarticular la continuidad espacial urbana" (p. 7). Este crecimiento espontáneo dificulta la integración funcional del territorio urbano, desaprovechando los equipamientos existentes y generando altos costos en la extensión de la infraestructura y los servicios públicos domiciliarios que tienen tramos ociosos.

Estos fenómenos se ven plasmados en la valorización de algunos terrenos y en el abandono o la desvalorización de otros. Los primeros usados para el desarrollo e instalación de actividades competitivas (barrios cerrados, desarrollos inmobiliarios, shoppings, hipermercados, estaciones de servicios múltiples, estaciones de transferencia de mercancías, playas de estacionamiento de vehículos particulares y de carga, barrios privados) y los segundos para el establecimiento residencial de grupos de población de bajos ingresos y para el desarrollo de actividades de supervivencia como el "cirujeo" en basurales y la cría de cerdos.

Se observa, entonces, un territorio fuertemente fragmentado, diferenciándose claramente los barrios de pobres y ricos, dando cuenta de la segregación social creciente. Se visualiza una tendencia de los barrios privados a ubicarse en la periferia urbana hacia el oeste, sur y sureste. Hacia el sur y sureste se produce una invasión de tierras agrícolas, mientras que hacia el oeste se avanza sobre el piedemonte. A su vez, los barrios de grupos de bajos recursos también se instalan en la periferia, aunque principalmente en la zona oeste. En palabras de Dalla Torre y Ghilardi (2012):

Es así que en varios espacios de la periferia se superponen barrios de élites junto a barrios pobres, mostrando una nueva dualidad "periferia-periferia". Esta "convivencia espacial", no obstante, no se traduce en una "convivencia social", siendo que las barreras materiales e inmateriales son cada vez más profundas (p. 21)

En el área en estudio ocurre el fenómeno explicado por Trivelli (2004):

La autosegregación en el espacio urbano obedece a una estrategia deliberada de mejoramiento de las condiciones de vida con base en la concentración territorial de la demanda, capaz de atraer la oferta de las cosas buenas

1 Se utiliza la figura de la mancha de aceite como comparación al crecimiento urbano ya que este se da de forma no continua y los espacios intermedios se van llenando de la misma forma como lo hace una mancha de aceite al crecer, tiende a unir las distintas gotas más pequeñas que la rodean (Ducci, 1998). 
y escasas que se pueden obtener con dinero a través del mercado, pero también para ejercer influencia y presión sobre las autoridades urbanas a fin de obtener las inversiones y los servicios necesarios, así como para excluir aquellas actividades y funciones urbanas que generan externalidades negativas (p. 26)

Este fenómeno hace más pronunciado el desequilibrio territorial ya que los grupos de gran poder económico ejercen presión para beneficiarse con la expansión de la infraestructura y los equipamientos urbanos. Estos actores tienen suficiente influencia sobre el aparato estatal para orientar a su favor las obras de infraestructura pública, en detrimento de los grupos más vulnerables. Es así como, dichos territorios cuentan con todos los servicios básicos y se benefician de las externalidades positivas de equipamientos como espacios verdes. Un agravante es que las zonas donde habita la población de mayores ingresos tienen una densidad poblacional baja, por lo que el costo de ampliación de dicha infraestructura es alto. La utilización de fondos públicos para la expansión de los servicios urbanos adopta así un carácter regresivo (Trivelli, 2004).

El AMM se constituye, entonces, como una ciudad intermedia, en la cual algunos procesos propios de las grandes ciudades centrales (Buenos Aires, Santiago de Chile, San Pablo) han comenzado a desarrollarse a gran velocidad. Es decir, es una ciudad con alta concentración de actividades administrativas, políticas, comerciales y financieras (a la vez que existen subcentros formando una región policéntrica) y de dimensión regional, en donde se detectan fuertes procesos de dispersión y de discontinuidad del tejido urbano, muy fragmentada espacial y socialmente, y con crecientes problemas de congestión vehicular y contaminación ambiental. Estos fenómenos dan cuenta del tamaño no óptimo del AMM para sus características intrínsecas.

\section{Forma urbana}

Desde el enfoque del desarrollo urbano sostenible se promueve el modelo de ciudades compactas. Estas realizan una ocupación espacial del territorio reducida por lo que tienen mezcla de usos del suelo, son territorios heterogéneos en donde las relaciones humanas son más fluidas. Las desventajas que se asocian con el modelo de ciudad dispersa tienen que ver con la extensión espontánea y creciente de la misma, que genera ámbitos territoriales parcialmente urbanizados, en los que se alternan zonas edificadas con espacios vacíos. Se observa que esta expansión, en general, no responde a un plan que prevea la disposición conveniente de las infraestructuras. Es decir, el inconveniente no es solamente la ampliación de la mancha urbana, sino también que esta no está consolidada y que la expansión es espontánea.

El Амм ha sufrido un proceso histórico de expansión acelerada, presentando dos antecedentes de relevancia que lo acentúan. Por un lado, la llegada del ferrocarril en 1885 y, por otro, el uso masivo del automóvil particular desde 1920. Sin embargo, este proceso se profundiza con la expansión residencial espontánea que comenzó en 1990 y que ha ido dejando espacios intersticiales vacíos. Esta es una de las razones por lo que se puede pensar que el caso en estudio responde o se aproxima a la alternativa de ciudad dispersa. 
Para evaluar cuantitativamente estas consideraciones, se utilizan dos indicadores: área urbana por habitante y crecimiento de la mancha urbana.

\section{Área urbana por habitante}

Este indicador se define como el espacio urbano disponible para cada habitante, es la superficie que en promedio le corresponde a cada habitante del sistema urbano. Mientras mayor sea su valor, mayor es el grado de dispersión en un territorio. Su objetivo es visualizar el reparto del espacio urbano en todo el territorio de la ciudad.

$\mathrm{Su}$ fórmula de cálculo es:

Área urbana por habitante $=$ superficie urbana en metros cuadrados / cantidad de habitantes urbanos

El área urbana por habitante se calcula a escala departamental utilizando datos georreferenciados del censo 2010. Siguiendo el criterio del informe de la Agencia de Ecología Urbana de Barcelona (2010), se considera como parámetro de sostenibilidad a un valor de entre 30 a 40 metros cuadrados por habitante.

En el Aмм se detectan valores muy superiores a este parámetro (figura 3), es decir, en la mayor parte del territorio hay una disponibilidad de más de 100 metros cuadrados por habitante.

Considerando este indicador, se detecta que el Амм tiende hacia un modelo de ciudad dispersa.

\section{Crecimiento de la mancha urbana}

Como complemento del área urbana por habitante se analiza el crecimiento de la mancha urbana a lo largo del tiempo. Este indicador se define como el porcentaje de incremento de superficie (hectáreas) de mancha urbana por periodo censal. En otras palabras, es el porcentaje de superficie que se incorpora al uso urbano. El objetivo es detectar si dicho crecimiento se ha producido a una tasa constante, a una tasa creciente o decreciente.

La fórmula de cálculo es la siguiente:

Crecimiento de la mancha urbana $=$ cantidad de hectáreas de la mancha urbana de un periodo censal / cantidad de hectáreas que se incorporaron a la mancha urbana en el siguiente periodo censal.

Para el cálculo de este indicador se utilizaron datos de superficie de la mancha urbana por periodo censal suministrados por el Instituto CIFOT y datos de población provistos por la encuesta permanente de hogares y censos poblacionales 2001 y 2010.

Se observa que en el АMм la superficie de espacio urbano se ha incrementado ininterrumpidamente a lo largo del tiempo (tabla 2 y figura 4). Este crecimiento ha sido a tasa creciente entre los años 1971 y 2001. Es decir, se afirma la tendencia del AMM hacia un modelo de ciudad no compacto sino difuso. 
FIGURA 3. ÁREA URBANA POR HABITANTE POR DEPARTAMENTO PARA EL AMM, 2010

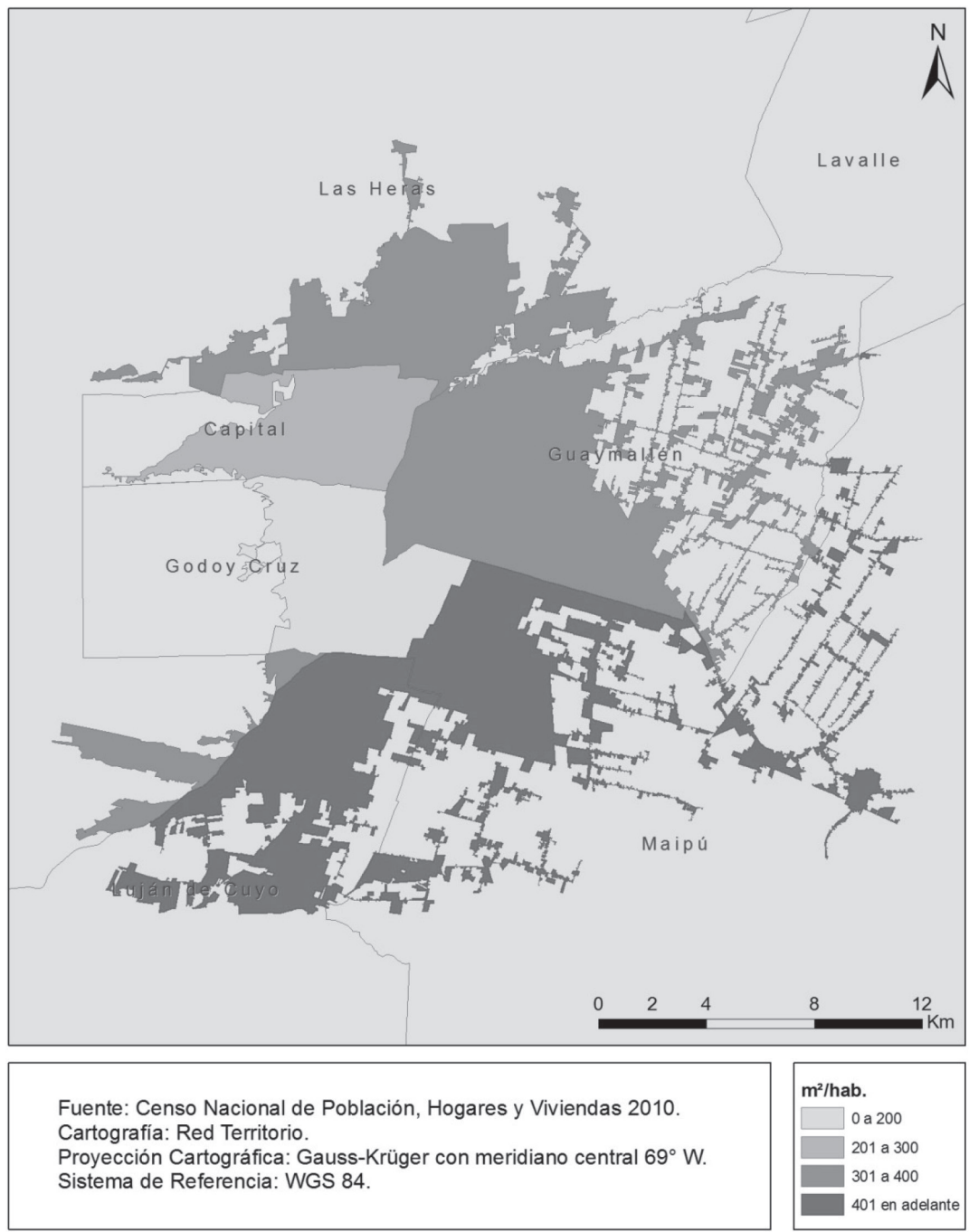

Fuente: Red Territorio (2013).

\section{Mezcla de usos}

Originalmente, la zonificación tuvo como fin hacer que las ciudades fueran funcionales y que cada actividad urbana tuviera una localización y condiciones ambientales adecuadas a sus exigencias (Le Corbusier, 1957). Así se evita que los impactos de algunas actividades o usos repercutan negativamente en otras cuando están muy próximas entre sí. En palabras de Sabatini (1998): 
TABLA 2. CRECIMIENTO DE LA MANCHA URBANA

\begin{tabular}{|c|c|c|c|c|}
\hline Periodo censal & $\begin{array}{c}\text { Superficie total de la } \\
\text { ciudad (en hectáreas) }\end{array}$ & $\begin{array}{c}\text { Incremento del periodo } \\
\text { (en hectáreas) }\end{array}$ & $\begin{array}{c}\text { Incremento } \\
\text { porcentual }\end{array}$ & $\begin{array}{c}\text { Incremento porcentual de la po- } \\
\text { blación según periodo censal }\end{array}$ \\
\hline $1952-1960$ & 3.635 & 1.752 & 93,04 & - \\
\hline $1961-1970$ & 5.843 & 2.208 & 60,74 & - \\
\hline $1971-1980$ & 7.802 & 1.959 & 33,53 & 21,51 \\
\hline $1981-1991$ & 13.517 & 5.715 & 73,25 & 9,48 \\
\hline $1992-2001$ & 24.531 & 11.014 & 81,48 & 10,19 \\
\hline $2002-2010$ & 31.330 & 6.799 & 27,72 & \\
\hline
\end{tabular}

Fuente: adaptación de figura 2 de Dalla Torre y Ghilardi (2012, p. 17).

FIGURA 4. CRECIMIENTO DE LA MANCHA URBANA EN EL AMM

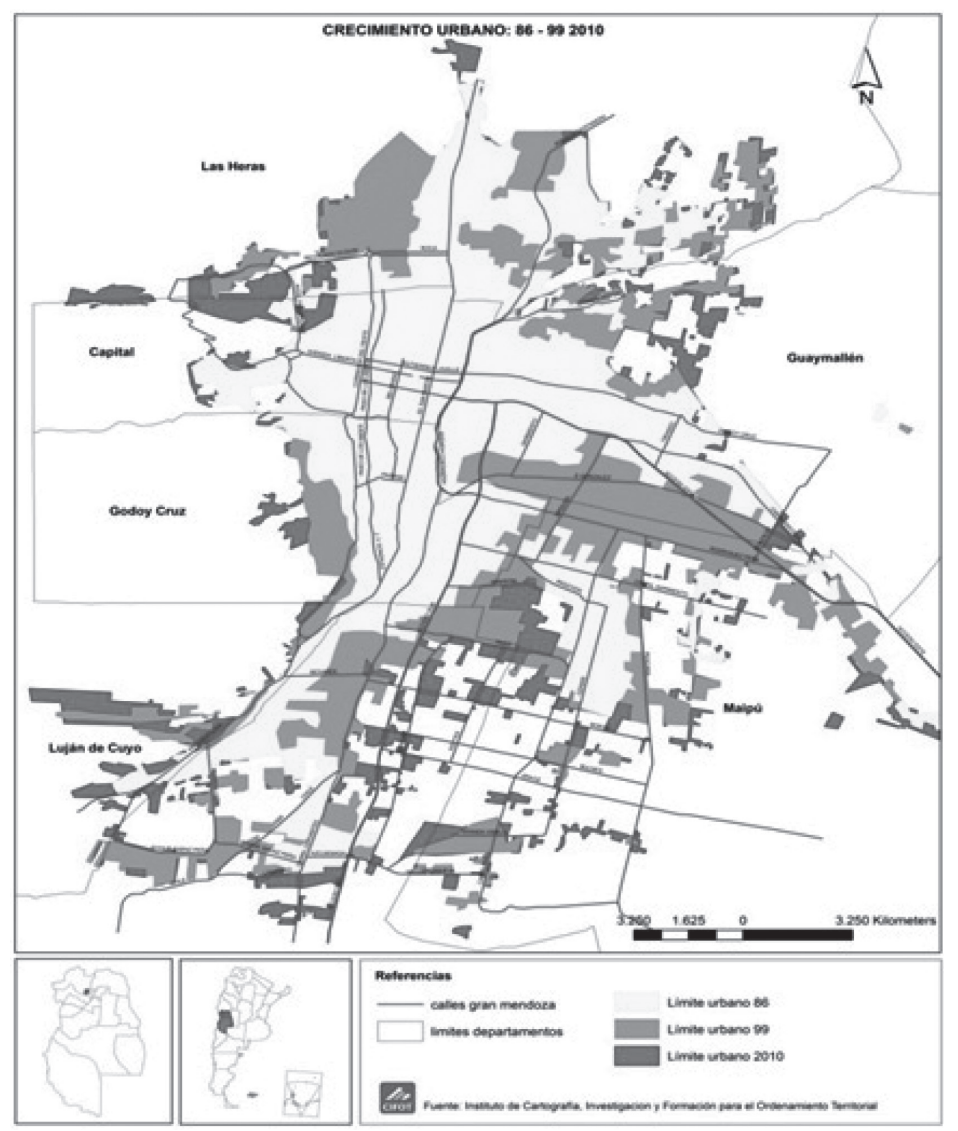

Fuente: Gudiño (2013). 
La zonificación, que es la esencia de la planificación urbana tradicional y que consiste en separar espacialmente actividades que se entorpecen entre sí, sigue siendo necesaria. El desarrollo tecnológico no ha sido tan importante ni está tan difundido en nuestras sociedades en desarrollo como para eliminar las externalidades físico-ambientales de unas actividades sobre otras. Esta es la razón para que las propuestas de planificación urbana estratégica reserven un rol para la vieja forma de normar los usos del suelo. Sin embargo, también es necesario seńalar que el avance tecnológico permitiría usos mixtos del suelo en un grado mucho mayor que el actual. Ello traería beneficios en términos de reducción de viajes, de integración social, de creatividad económica y de seguridad ciudadana (p. 143)

Es decir, para definir la zonificación, la localización de usos y la compatibilidad de actividades deberían evaluarse según las condiciones ambientales que requiere cada actividad. Es es, el problema de la coexistencia de actividades debería resolverse según los impactos negativos que tiene la práctica de cada una de ellas y no según la procedencia de dicho impacto. La zonificación debería clasificar las actividades por el efecto que producen en el territorio y no por el tipo de tareas que realiza. De este modo, podrían convivir contiguamente residencias con industrias de bajo impacto ambiental, y separarse y localizarse en áreas específicas únicamente aquellas actividades cuyos impactos son claramente incompatibles con el resto de los usos.

En la zonificación del AMM se hace una clara diferenciación entre los espacios destinados a industria, parques, residencia y comercio, existiendo zonas para el uso combinado solo de las dos últimas actividades (figura 5).
Sin embargo, se observa que en determinadas áreas los usos del suelo son en gran proporción mixtos, mezclándose actividades de servicios financieros, comerciales, administrativos e incluso industriales con la residencia. Según un informe del año 2006, del Instituto de Desarrollo Industrial, Tecnológico y de Servicios (IDITS) de Mendoza, un 82,2\% de las industrias de la provincia se encuentra localizado fuera de parques, áreas y zonas industriales, emplazándose gran cantidad de ellas en el área metropolitana. Este fenómeno resulta una ventaja desde la perspectiva de la movilidad ya que supone mezcla de usos y, por ende, menores distancias entre la residencia y las fuentes de empleo, a la vez que no presenta inconvenientes desde la óptica ambiental. Cabe aclarar que las industrias con grandes impactos negativos sobre el ambiente, y que por tanto son incompatibles para coexistir con la residencia, están separadas del centro urbano y ubicadas dentro de parques, zonas y áreas industriales.

Para analizar estos aspectos con mayor precisión se utilizan dos indicadores: proximidad a equipamientos básicos y superficie de espacios verdes por habitante.

\section{Proximidad a equipamientos básicos}

El indicador de proximidad a equipamientos básicos da una idea de la disponibilidad y distribución de equipamientos en el territorio urbano. Hace referencia a una proximidad simultánea, es decir, mide cuánta superficie urbana se encuentra servida por varios tipos de equipamiento a la vez. Indica el porcentaje de superficie urbana que cuenta 
FIGURA 5. ZONIFICACIÓN DEL AMM

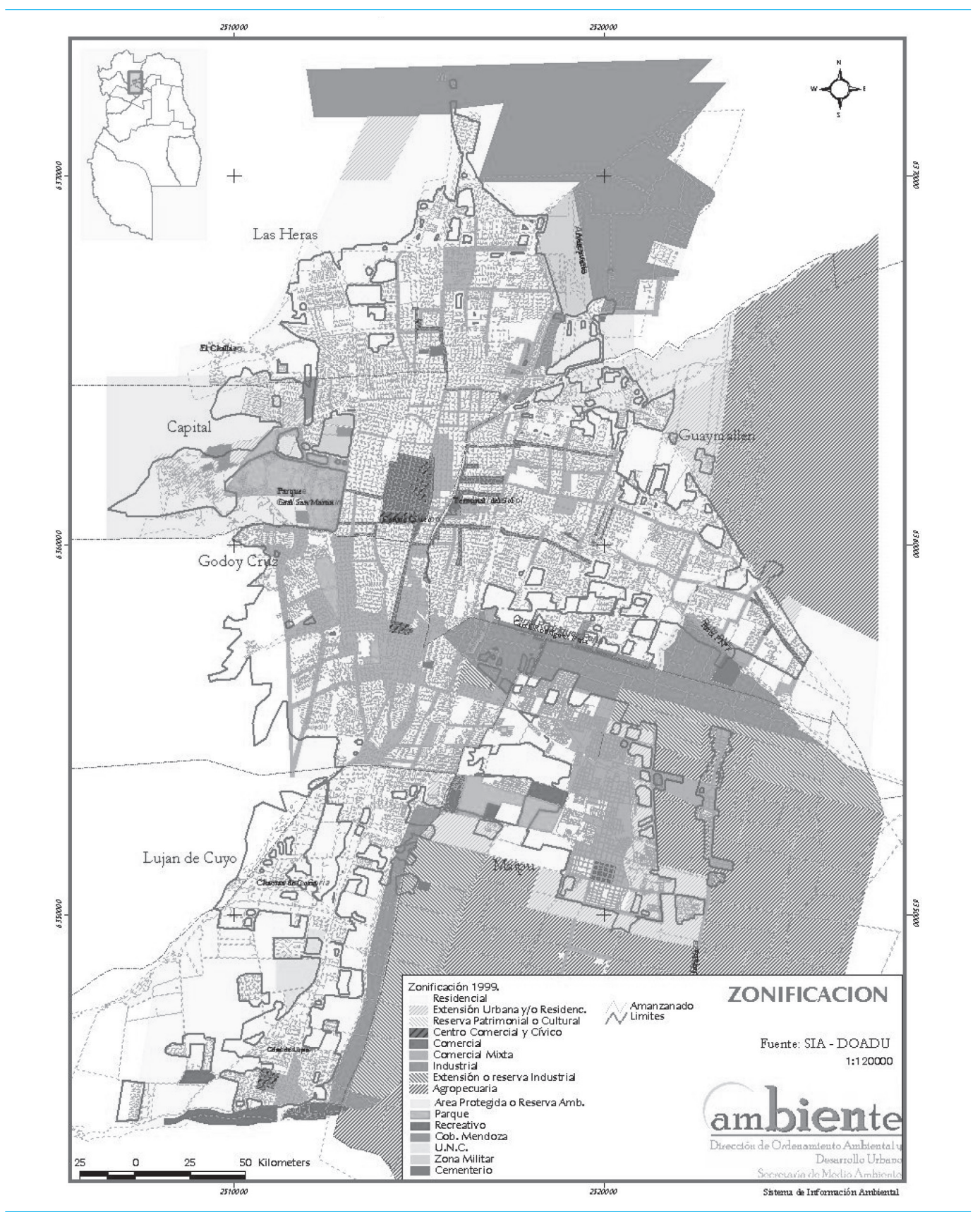

Fuente: Ministerio de Transporte de la provincia de Mendoza, 2006. 
con dotación de varios tipos de equipamiento. Tiene como objetivo informar sobre el grado de mezcla de usos del suelo.

Su fórmula de cálculo es la siguiente:

Proximidad a equipamientos básicos = superficie urbana con cobertura simultánea de equipamientos/superficie urbana total

En este trabajo, y por razones de disponibilidad de la información, se toman solo dos tipos de equipamiento básico: educación y salud. Para educación se consideran todos los establecimientos de educación primaria y secundaria, sean privados o públicos. Para salud, se consideran todos los establecimientos, sin importar su grado de complejidad (hospitales, clínicas y centros de atención primaria). Una vez detectados estos establecimientos y georreferenciados a través de un sistema de información geográfica, se calcula su área de influencia de 600 metros a la redonda (se realiza un buffer de 600 metros que equivale a un trayecto de 10 minutos a pie) y se seleccionan las áreas de intersección, es decir, se consideran las áreas en las que se puede acceder simultáneamente a servicios de salud y de educación. Posteriormente, se estima la importancia de esta superficie en la superficie total urbana. Este indicador se calcula por departamento.

La situación ideal sería una proximidad simultánea de entre 75 y $100 \%$ (figura 6). Esta circunstancia se observa en los departamentos de Capital y Godoy Cruz, pero no en los restantes. En Las Heras, Guaymallén y Maipú existe una proximidad a los equipamientos básicos de entre 50 y 75 \%, y en Luján de Cuyo solo alcanza el $50 \%$. Es decir, considerando que este indicador de proximidad simultánea a equipamientos básicos representa la mezcla de usos del territorio, se observa que en la mayor parte del territorio del AMM no existe una adecuada mezcla de usos del suelo.

\section{Superficie de espacios verdes por habitante}

El indicador de superficie de espacios verdes por habitante relaciona a las superficies verdes existentes en un territorio urbano con la población que reside en él. Se entiende como espacio verde urbano aquel espacio público dotado de cobertura vegetal y al cual la población puede acceder gratuitamente. En este trabajo se consideran plazas y parques. El objetivo de este indicador es evaluar la distribución de las áreas verdes en el sistema urbano, determinando la disponibilidad de estos para los habitantes del mismo. Una distribución uniforme de espacios verdes en el territorio metropolitano y una suficiente cantidad de los mismos, da cuenta de una adecuada mezcla de usos del suelo.

La fórmula de cálculo es:

Espacios verdes por habitante $=$ superficie de espacios verdes (parques, plazas) en metros cuadrados / cantidad de habitantes

Para estimar este indicador se tomaron los datos de población del censo 2010 por departamento. A su vez, a partir de la cartografía del Instituto CIFOT se calcularon las superficies de áreas verdes por departamento, considerando como tal a las plazas y los parques. 
FIGURA 6. PROXIMIDAD A EQUIPAMIENTOS BÁSICOS POR DEPARTAMENTO DEL AMM

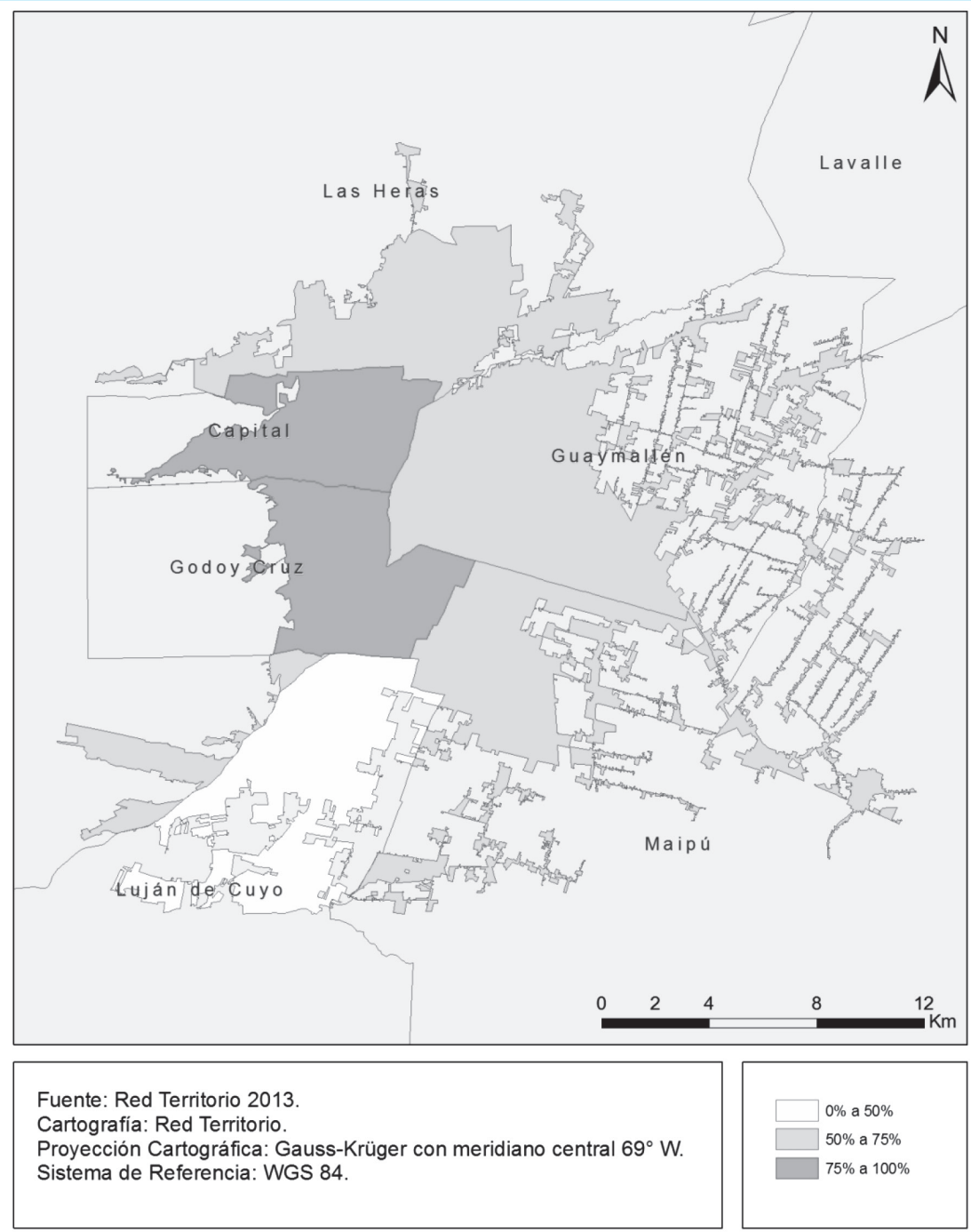

Fuente: Red Territorio (2013).

Según la Agencia de Ecología Urbana de Barcelona (2010), cada sistema urbano debe contar con al menos 10 metros cuadrados de espacios verdes por habitante, siendo el valor óptimo de 15 metros cuadrados por habitante.
En este marco, en el AMM el departamento que presenta las mejores condiciones es Capital, con más de 10 metros cuadrados por habitante (figura 7). Esta situación puede deberse a que en dicha área se encuentra el Parque General 
FIGURA 7. ESPACIOS VERDES POR HABITANTE POR DEPARTAMENTO DEL AMM, 2010

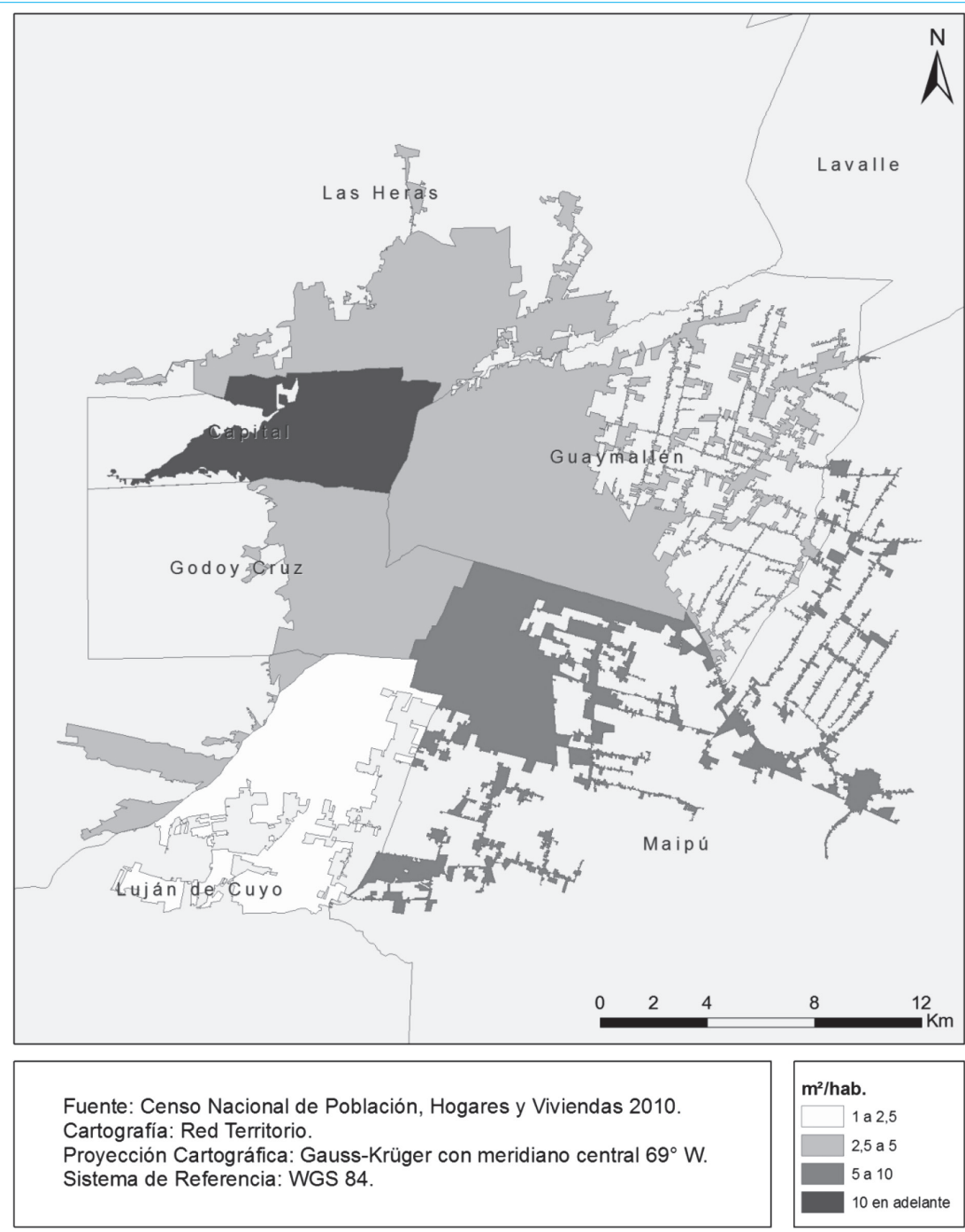

Fuente: Red Territorio (2013).

San Martín, uno de los espacios verdes de mayor superficie en el sistema urbano. En el departamento de Maipú se detecta una situación relativamente favorable, ya que cuenta con entre 5 y 10 metros cuadrados de superficie verde por habitante. Los departamentos de Godoy Cruz, Las Heras y Guaymallén requieren del doble de espacios verdes para alcanzar el mínimo aceptable. Y el departamento de Luján de Cuyo es el que se encuentra en peor situación. 
Estas circunstancias muestran que el AMM no cuenta con suficientes espacios verdes por habitante en la mayor parte de su territorio y que la distribución de los mismos no es equitativa.

\section{Densidades de uso del suelo}

La reducción en la densidad de uso del suelo provoca aumento del consumo energético, de los costos de extensión de infraestructura para servicios de agua, gas, electricidad y alcantarillado, y desincentiva el uso de medios colectivos de transporte. Es decir, menores densidades de uso del suelo no son favorables para la sostenibilidad de las ciudades. Para analizar la densidad de usos del suelo, en este trabajo, se consideran dos indicadores: densidad poblacional y densidad de vivienda.

\section{Densidad poblacional}

La densidad poblacional se define como el número de habitantes por unidad de superficie (en este caso hectáreas) de suelo urbanizado. A través de la densidad poblacional urbana se puede observar la configuración de la ciudad, se puede apreciar el modo en que se ordena el territorio. Por ello, el objetivo de este indicador es comprobar el grado de dispersión de la ciudad en el territorio.

La fórmula de cálculo es:

Densidad poblacional $=$ número de habitantes $/$ hectáreas

Para el caso en estudio se calculó la densidad poblacional del área urbana por departamento. Se utilizó información del censo poblacional 2010. A través de un proceso de georreferenciación de los datos proporcionados por dichos censos se obtiene la ubicación y el número de habitantes total para cada una de las áreas que se van a analizar. El espacio urbano total se determina a partir de criterios cartográficos definidos por el Instituto CIFOT.

Según la Agencia de Ecología Urbana de Barcelona (2010), el rango de densidad poblacional urbana adecuado varía entre 250 y 350 habitantes por hectárea. Las densidades que se encuentren muy por arriba o por debajo de estos valores no son deseables en un modelo de sostenibilidad. En el primer caso, porque existiría algún tipo de congestión en términos de espacios públicos y servicios. En el segundo caso, porque la tipología sería dispersa generando un mayor consumo de recursos, mayores costos en expansión de los servicios y menores posibilidades de intercambios de personas, bienes y actividades.

Según datos de la ocde del 2005, París es la ciudad con mayor densidad poblacional, y apenas supera los 200 habitantes por hectárea (figura 8).

Considerando datos más actualizados, según el Instituto de Estadística de Catalunya (2013), la densidad poblacional de Barcelona es de 159,06 habitantes por hectárea, es decir, se encuentra por debajo del valor óptimo. Asimismo, la ciudad de Copenhague, considerada la mejor ciudad para vivir en el mundo y referente por la eficiencia de su sistema integrado de transporte, tiene una densidad poblacional de 59,09 habitantes por hectárea (2011). Como ejemplo latinoamericano se considera a la ciudad del Distrito Federal de México, cuya densidad poblacional es de 
FIGURA 8. CIUDADES CON ALTAS DENSIDADES DE POBLACIÓN (HABITANTES POR KM²) 2005

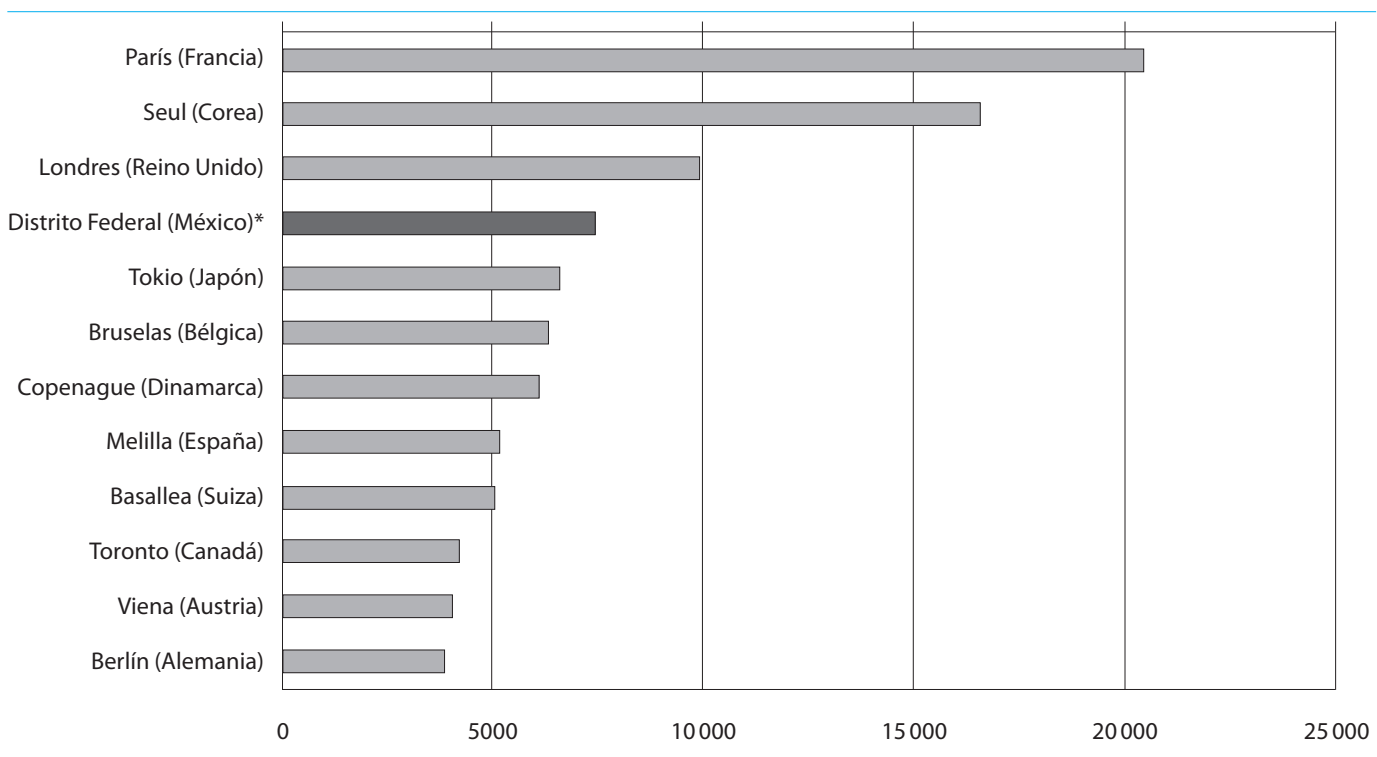

Fuente: OCDE (s. f.).

59,20 habitantes por hectárea (Instituto Nacional de Estadística y Geografía de México, 2010). Todos estos casos se encuentran muy por debajo de los valores óptimos de densidad poblacional establecidos por la Agencia de Ecología Urbana de Barcelona.

Según datos del censo poblacional 2010, el AMM tiene en promedio una densidad de población de 31,60 habitantes por hectárea. De acuerdo con los parámetros establecidos esta densidad es baja por lo que se detecta una gran dispersión (figura 11).

Para un análisis más detallado, se considera la densidad poblacional del АMм por departamento (figura 9). Se observa que el municipio con el mayor índice es Godoy Cruz, alcanzando un valor de 51 habitantes por hectárea. No obstante, este se encuentra muy por debajo de los valores considerados óptimos para los fines de la sustentabilidad. Los departamentos de Capital y Guaymallén presentan niveles similares al promedio, y Luján de Cuyo y Maipú tienen densidades de población muy por debajo de este nivel. Se observa, entonces, que la ciudad se ha expandido en dirección de estos últimos departamentos, hacia el sureste.

Según lo analizado, el AMM se aproxima al modelo de ciudad dispersa y no sostenible, ya que cuenta, en promedio, con densidades de población bajas.

\section{DENSIDAD DE VIVIENDAS}

La densidad de viviendas se define como el número de viviendas por unidad de superficie (en este caso hectáreas). Este indicador 
FIGURA 9. DENSIDAD POBLACIONAL POR DEPARTAMENTO DEL AMM, 2010

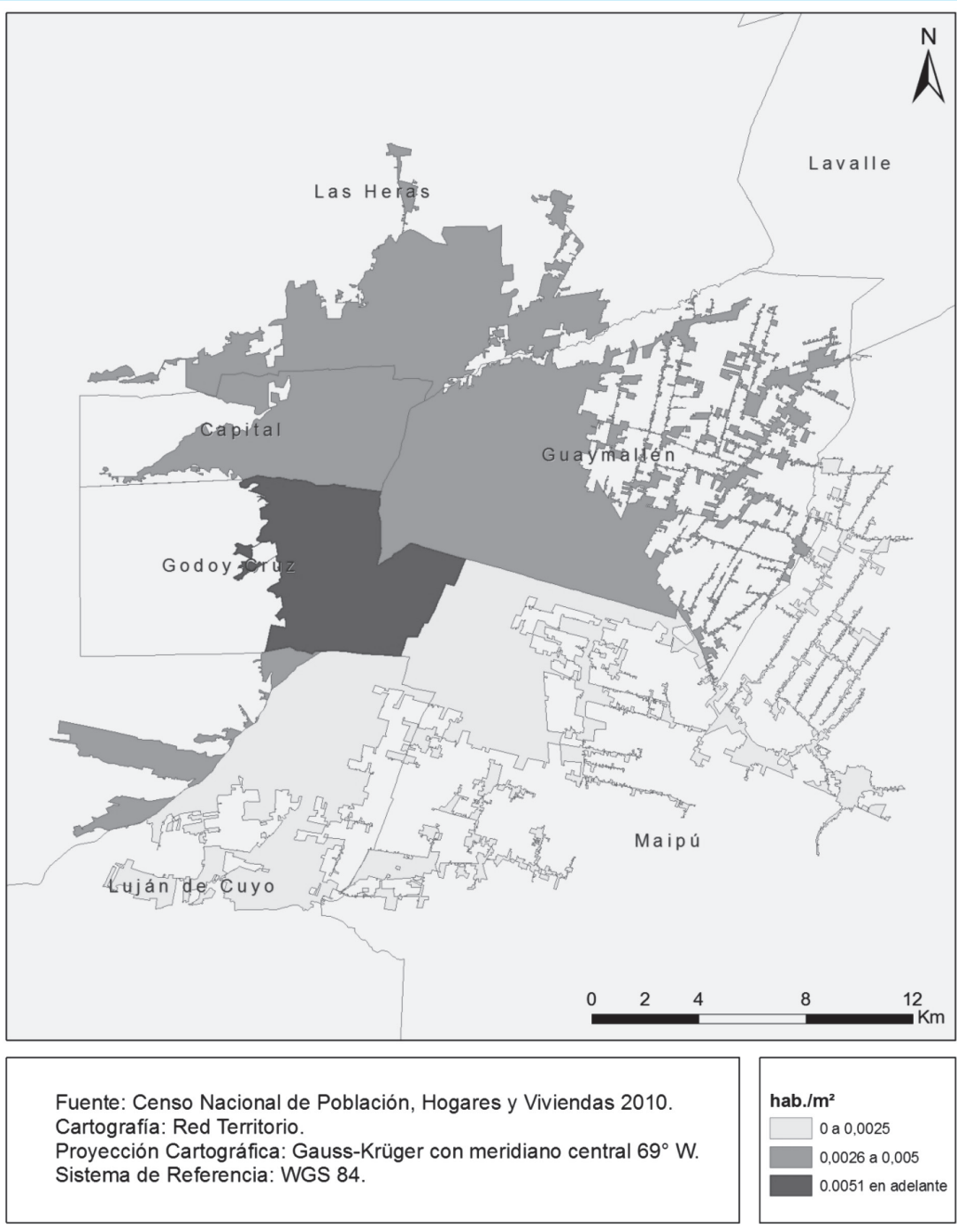

Fuente: Red Territorio (2013).

tiene como objetivo detectar la ocupación media que existe en la ciudad.

Su fórmula de cálculo es:

Densidad de viviendas = número de viviendas / hectárea
Para calcular este indicador se consideró la escala departamental, utilizando información del censo nacional de 2010. Al igual que para la densidad poblacional, se realizó un proceso de georreferenciación de los datos del 
censo obteniendo la ubicación y la cantidad de viviendas totales para cada una de las áreas por analizar. Al igual que para el resto de los indicadores, el espacio urbano total se determinó según criterios cartográficos definidos por especialistas del Instituto CIFOT.

Existen diversos parámetros para este indicador. Según la Commission for Architecture \& the Built Environment de Gran Bretaña, la densidad de vivienda óptima es de 69 viviendas por hectárea. Según la Comisión Económica para América Latina (2002) la densidad de viviendas debería ser de 200 viviendas por hectárea, y según el Libro Verde sobre medio ambiente urbano (Comisión de las Comunidades Europeas, 2007) debería ser de 75 viviendas por hectáreas.

En el Aмm cualquiera de estos parámetros resulta muy alto respecto de las densidades de vivienda que se encuentran en su territorio. Se detecta que en los departamentos de mayor densidad (Capital y Godoy Cruz) esta apenas supera las 1,1 viviendas por hectárea (figura 10). Es decir, la densidad de viviendas en el AMM se encuentra muy por debajo de los parámetros mencionados, dando cuenta de la gran dispersión urbana.

Si bien el Aмm no ha tenido nunca una densidad edilicia alta, desde la década de los noventa comenzó un proceso de dispersión que ha hecho que estos niveles disminuyan aún más. Dicho proceso se debió a la búsqueda de residencias unifamiliares con mejores condiciones ambientales, viviendas con jardín propio y lejos del ruido y la contaminación de la ciudad.

En síntesis, debido a la baja densidad poblacional y de vivienda, se detecta que el AMM se aproxima a un modelo de ciudad dispersa.

\section{RESULTADOS DE LA EVALUACIÓN DE SOSTENIBILIDAD DE LA ESTRUCTURA URBANA}

De acuerdo con los indicadores analizados y la ponderación que a cada uno de ellos se le asigna, se afirma que el sistema urbano en estudio no presenta ninguna de las características espaciales deseadas de sustentabilidad. Es decir, ni el tamaño de la ciudad es el óptimo, ni la forma urbana tiende a ser compacta, ni la mezcla de usos es suficiente, ni la densidad de usos del suelo es la adecuada (tabla 3). Todos los indicadores en su conjunto asumen un valor de cero, por lo que se encuentra en el intervalo de no sustentabilidad.

Si no se generan políticas efectivas de ordenamiento del territorio, este modelo de ciudad no sustentable se profundizará y cada vez requerirá de mayores esfuerzos para revertir la tendencia.

Estos resultados dan cuenta de la realidad cuantitativa del área estudiada, y ponen en relieve las características de la estructura urbana. Es importante aclarar que la metodología empleada es una adaptación de aquella que propone Camagni. Este autor considera que para analizar la sostenibilidad del sistema urbano no solo es relevante estudiar la estructura urbana sino también el comportamiento de la ciudad. Esta dimensión de comportamiento o dinámica urbana se omite en este trabajo, por razones de extensión del texto, priorizando solo el estudio de la estructura urbana. Asimismo, la evaluación de cada variable que compone la estructura urbana se realiza a partir de indicadores elegidos por su relevancia y a partir de la información disponible. Seguramente se- 
FIGURA 10. DENSIDAD DE VIVIENDAS POR DEPARTAMENTO DEL AMM, 2010

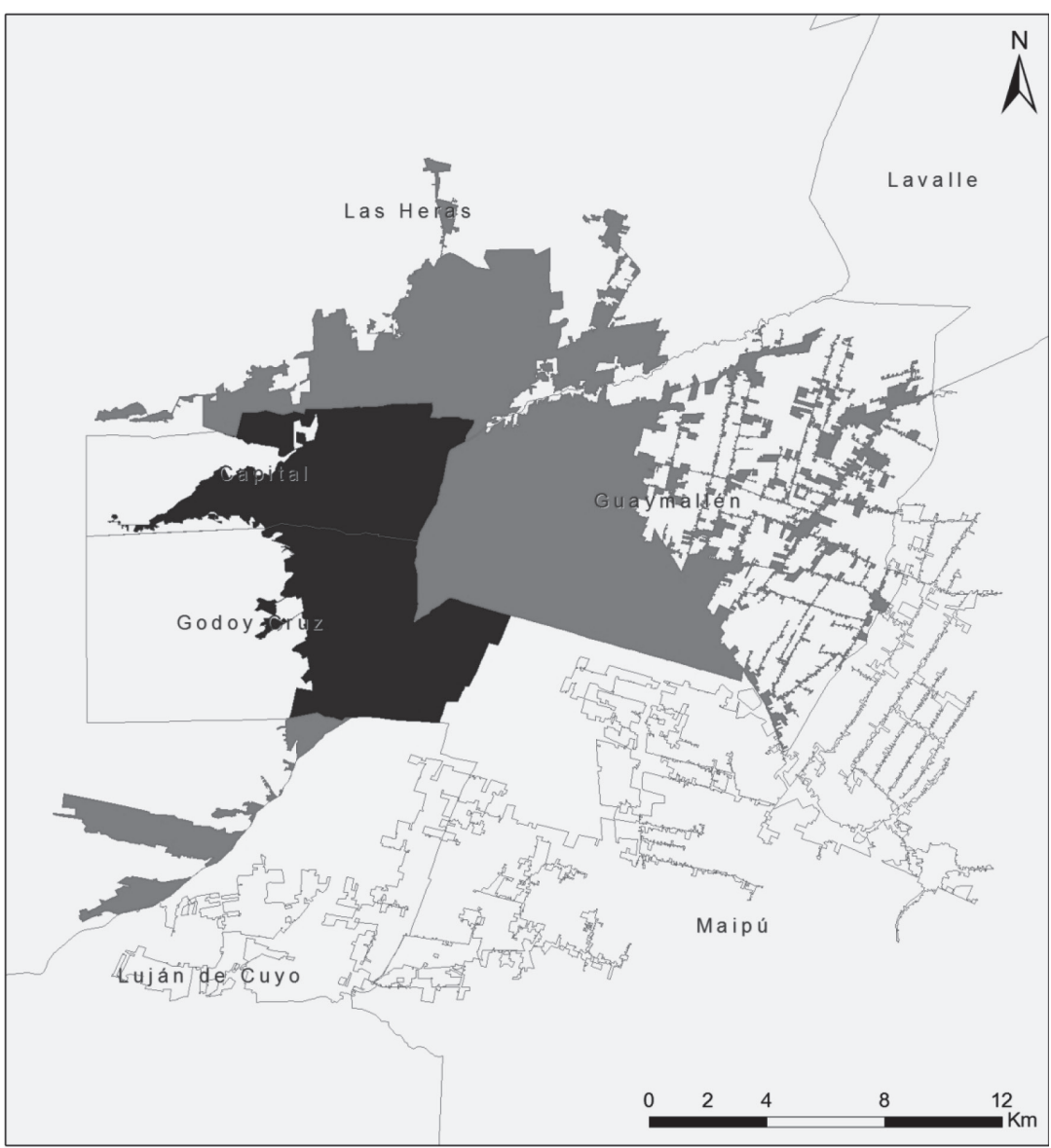

Fuente: Censo Nacional de Población, Hogares y Viviendas. 2010. Cartografia: Red Territorio.

Proyección Cartográfica: Gauss-Krüger con meridiano central $69^{\circ} \mathrm{W}$. Sistema de Referencia: WGS 84

ría de interés adicionar indicadores que dieran más precisión sobre algunos aspectos de las variables mencionadas, pero la inexistencia de información completa y actualizada en el área en estudio es una gran limitante. Finalmente, se detecta como debilidad de esta metodología la ausencia de consideraciones sobre la relación del sistema urbano con el entorno natural, dejando de lado, entonces, la evaluación de la resiliencia del mismo. 
TABLA 3. CARACTERÍSTICAS ESPACIALES DEL AMM

\begin{tabular}{|c|c|c|c|}
\hline Variable & Indicador & Atributo & Ponderación \\
\hline \multirow{2}{*}{$\begin{array}{l}\text { Tamaño } \\
\text { de la ciu- } \\
\text { dad }\end{array}$} & \multirow{2}{*}{$\begin{array}{l}\text { Dimensión } \\
\text { de la ciudad }\end{array}$} & Adecuada & \\
\hline & & No adecuada & 0 \\
\hline \multirow{4}{*}{$\begin{array}{l}\text { Forma } \\
\text { urbana }\end{array}$} & \multirow{2}{*}{$\begin{array}{l}\text { Área urbana } \\
\text { por habi- } \\
\text { tante }\end{array}$} & Adecuada & \\
\hline & & No adecuada & 0 \\
\hline & \multirow{2}{*}{$\begin{array}{l}\text { Crecimiento } \\
\text { de la man- } \\
\text { cha urbana }\end{array}$} & No acelerado & \\
\hline & & Acelerado & 0 \\
\hline \multirow{4}{*}{$\begin{array}{l}\text { Mezcla } \\
\text { de usos }\end{array}$} & \multirow{2}{*}{$\begin{array}{l}\text { Espacios } \\
\text { verdes por } \\
\text { habitante }\end{array}$} & Suficientes & \\
\hline & & $\begin{array}{l}\text { No suficien- } \\
\text { tes }\end{array}$ & 0 \\
\hline & \multirow{2}{*}{$\begin{array}{l}\text { Proximidad a } \\
\text { equipamien- } \\
\text { tos básicos }\end{array}$} & Suficientes & \\
\hline & & $\begin{array}{l}\text { No suficien- } \\
\text { tes }\end{array}$ & 0 \\
\hline \multirow{6}{*}{$\begin{array}{l}\text { Densidad } \\
\text { de uso } \\
\text { del suelo }\end{array}$} & \multirow{2}{*}{$\begin{array}{l}\text { Densidad } \\
\text { poblacional }\end{array}$} & Adecuada & \\
\hline & & No adecuada & 0 \\
\hline & \multirow{2}{*}{$\begin{array}{l}\text { Densidad de } \\
\text { viviendas }\end{array}$} & Adecuada & \\
\hline & & No adecuada & 0 \\
\hline & \multirow{2}{*}{$\begin{array}{l}\text { Característi- } \\
\text { cas espacia- } \\
\text { les del siste- } \\
\text { ma urbano }\end{array}$} & Sustentables & 0,$75 ; 1$ \\
\hline & & $\begin{array}{l}\text { No sustenta- } \\
\text { bles }\end{array}$ & $0 ; 0,75$ \\
\hline
\end{tabular}

Fuente: elaboración propia.

\section{REFLEXIONES FINALES}

Las características espaciales del AMM no dan cuenta de una ciudad sostenible. Se observa que el tamaño de la ciudad no es el óptimo. En ella se detectan procesos similares a los de las grandes ciudades: expansión urbana acelerada, fragmentación espacial y social y crecientes problemas de congestión vehicular y contaminación ambiental. El crecimiento de la ciudad ha sido explosivo y espontáneo, impidiendo que el resto de las dimensiones del territorio se adecuen al mismo. Estas características evidencian un tamaño no óptimo del área estudiada.

Respecto de la densidad de usos del suelo, el AMM presenta valores muy por debajo del parámetro óptimo, evidenciando una ciudad dispersa. Tiene densidades de población y de vivienda bajas. La primera disminuye a mayor distancia del núcleo central, siendo incluso baja en este núcleo. La segunda resulta también muy baja y se ve acentuada por la elección del estilo de vivienda unifamiliar con mejores condiciones ambientales.

La forma urbana del АмM tiende hacia un modelo disperso. Esta forma urbana se caracteriza por ser extensa y en expansión constante e indiscriminada, por tener un irracional consumo de energía y del espacio urbano, y por demandar continuamente la expansión de las infraestructuras. Esto se evidencia, a su vez, en las bajas densidades de población y de vivienda mencionadas. Este tipo de ciudad se fragmenta en espacios homogéneos, poco conectados, perjudicando el desarrollo del capital social. Dicha área, por sus características físico-naturales, se expande principalmente hacia el sur y sureste, invadiendo zonas productivas y con recursos naturales de gran valor.

Por último, la mezcla de usos del suelo en el Амм tiende a disminuir, y en la actualidad no es la óptima. Esta situación genera mayor necesidad de desplazamientos ya que se separan las actividades en el territorio, principalmente la residencia y el empleo. A su vez, los desplazamientos se concentran en el tiempo 
y en el espacio con consecuencias tales como congestión y contaminación.

El modelo de ciudad disperso, basado en la segregación y homogeneización de usos, con bajas densidades de población y edilicia, con ocupación espacial discontinua, con expansión constante e ilimitada, se caracteriza por el uso irracional de las energías, del espacio urbano, por la congestión y contaminación, la fragmentación social, la segregación espacial y la marginación. Todas estas, características de ciudades no sostenibles. Estos procesos son cada vez más frecuentes en el AMM, por lo que si no se toman medidas de ordenamiento del territorio la tendencia natural es acentuar la poca sostenibilidad del mismo generando mayor fragilidad y vulnerabilidad, y peores condiciones de vida para todos sus habitantes.

Esta ciudad no sostenible no favorece el crecimiento del bienestar y de la calidad de vida de sus habitantes, no facilita el vínculo sostenible con las áreas aledańas e impide la reducción de impactos negativos sobre el sistema natural.

Dichos factores, que dan cuenta de una ciudad no sostenible, suponen, asimismo, la ausencia de resiliencia o capacidad adaptativa. De esta manera, la tasa de consumo de recursos naturales de la ciudad es superior a la tasa de generación de los mismos en la naturaleza y a la tasa de absorción de los impactos negativos sobre ella.

\section{REFERENCIAS}

Acselrad, H. (1999). Sustentabilidad y ciudad. Eure, xxv (74), 35-46.
Agencia de Ecología Urbana de Barcelona (2010). Plan de indicadores de sostenibilidad urbana de VitoriaGasteiz. Barcelona: BCN Ecología.

Ayuntamiento de Málaga (2010). Agenda 21 Málaga. Indicadores de sostenibilidad. Servicio de Programas. Málaga: Observatorio de Medio Ambiente Urbano.

Bellet, C. y Llop, J. M. (2004). Miradas a otros espacios urbanos: las ciudades intermedias. Scripta Nova, VIII (165), 1-30.

Burguess, R. (2003). Ciudad y sostenibilidad: desarrollo urbano sostenible. Cuadernos de la CEPAL, 88, 193-214.

Camagni, R. (2005). Economía urbana. Barcelona: Antoni Bosch.

Comisión de las Comunidades Europeas (2007). Libro Verde. Hacia una nueva cultura de la movilidad urbana. Bruselas: сом.

Comisión Económica para América Latina (2002). Censo de población y vivienda. Recuperado de: http://www.cepal.org/cgi-bin/getProd.asp?xml=/ redatam/noticias/paginas/7/13277/P13277.

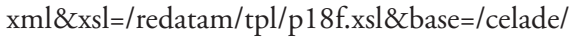
tpl/top-bottom_cen.xslt

Comisión Europea (1990). Libro Verde sobre el medio ambiente urbano. Comunicación de la Comisión al Consejo y al Parlamento. Bruselas: сом.

Dalla Torre, J. y Ghilardi, M. (2012). Aproximación a la ciudad dual. Fragmentación espacial y segregación material y simbólica en el área metropolitana de Mendoza, Argentina. Proyección, vi, 6-25.

Eibenschutz, R., \& Goya, C. (2009). Estudio de la integración urbana y social en la expansión reciente de las ciudades en México, 1996-2006: dimensión, características y soluciones. México, Sedesol/Uam-X/Miguel Ángel Porrúa.

Gobierno del Estado de Morelos (s. f.). Programa Estatal de Desarrollo Urbano 2007-2012. Diagnóstico 
del nivel de integración funcional del territorio. Morelos: Gobierno del Estado de Morelos.

Gudiño, M. E. (2013). Uso del suelo y planificación del transporte. Realidades, utopías y desafíos en el marco del ordenamiento del territorio. En I Congreso sobre Transporte Urbano, Sustentabilidad y Ordenamiento Territorial. Universidad Nacional de Cuyo y Ministerio de Transporte, Provincia de Mendoza.

Gudynas, E. (2009). Desarrollo sostenible: posturas contemporáneas y desafíos en la construcción del espacio urbano. Montevideo: Centro Latino Americano de Ecología Social.

Instituto de Estadística de Catalunya (2013). Recuperado de: http://www.idescat.cat/es/

Instituto de Políticas para el Transporte y el Desarrollo México (ITDP) (2013). Desarrollo orientado al transporte. Regenerar las ciudades mexicanas para mejorar la movilidad. D.F. México: ITDP y Embajada Británica en México.

Jenks, M., Burton, E. y Williams, K. (1996). The compact city a sustainable urban form. London: E\&F Spon.

Le Corbusier (1957). Mensaje a los estudiantes de arquitectura. Buenos Aires: Ediciones Infinito.

Marín Cots, P. et al. (2002). La configuración de la ciudad, compacta versus difusa. Málaga: OMAU. Recuperado de http://www.omau-malaga.com/ portal/index.php?id=174

Michelini, J. J. y Davies, C. (2009). Ciudades intermedias $y$ desarrollo territorial: un análisis exploratorio del caso argentino. Madrid: Grupo de Estudios sobre Desarrollo Urbano.

OCDE (s. f.). Mejores politicas para una vida mejor. Recuperado de http://www.oecd.org/centrodemexico /4lugarqueocupalaciudaddemexicoendensidadd epoblacionenlaocde.htm
OECD (2013). OeCD Regions at a Glance 2013. Washington: OECD Publishing. Recuperado de http:// www.keepeek.com/Digital-Asset-Management/ oecd/urban-rural-and-regional-development/ oecd-regions-at-a-glance-2013_reg_glance2013-en\#page4

Pozueta, J. (2000). Movilidad y planeamiento sostenible. Hacia una consideración inteligente del transporte y la movilidad en el planeamiento y el diseño urbano. Madrid: Instituto Juan de Herrera.

Razquin, O. y Pons, M. C. (1990). Estudio de planificación del transporte público de pasajeros Gran Mendoza. Seminario Uso racional de la energía en el transporte urbano y la planificación urbana. Agence: Subsecretaría de Energía de la Nación. Red Territorio. Observatorio de Desarrollo Territorial Sustentable para la Provincia de Mendoza (2013). Argentina: Mimeo.

Rueda Palenzuela, S. (1993). Ecología urbana. Madrid: Beta Editorial.

Rueda Palenzuela, S. (1999). Modelos e indicadores para ciudades más sostenibles. Taller sobre Indicadores de huella y calidad ambiental urbana. Fundación Fórum Ambiental. Cataluña: Departament de Medi Ambient de la Generalitat de Catalunya. Rueda Palenzuela, S. (2002). Modelos de ordenación del territorio más sostenibles. Barcelona: Fundació Forum Ambiental.

Sabatini, F. (1998). Direcciones para el futuro. En Ciudades intermedias de América Latina y el Caribe: propuestas para la gestión urbana. Santiago de Chile: Comisión Económica para América Latina y el Caribe (CEPAL).

Trivelli, P. (2004). Realidad y desafíos de la ciudad latinoamericana a principios del siglo xxI: equidad, competitividad, sustentabilidad y gobernabilidad. En Cuarto Curso Centroamericano de Gestión 
Urbana y Municipal. Washington: Instituto de Desarrollo Económico del Banco Mundial.

Urriza, G. y Garriz, E. (2014). ¿Expansión urbana o desarrollo compacto? Estado de situación en una ciudad intermedia: Bahía Blanca, Argentina. Revista Universitaria de Geografia, 23 (1-2), pp. 97-124.

Vapñarsky, C. (1995). Primacía y macrocefalia en la Argentina: la transformación del sistema de asentamiento urbano desde 1950. Desarrollo Económico, 35 (138), 227-254. 